\title{
Vitamina K: Metabolismo, Fontes e Interação com o Anticoagulante Varfarina
}

\section{Vitamin K: Metabolism, Sources and Interaction with the Anticoagulant Warfarin}

\author{
${\operatorname{Karin~} \mathrm{Klack}^{(1)} \text {, Jozélio Freire de Carvalho }}^{(2)}$
}

\section{RESUMO}

A vitamina K é lipossolúvel, principalmente, na coagulação sanguínea. Se apresenta sob as formas de filoquinona $\left(\mathrm{K}_{1}\right.$-predominante), dihidrofiloquinona $(\mathrm{dK})$, menaquinona $\left(\mathrm{K}_{2}\right)$ e menadiona $\left(\mathrm{K}_{3}\right)$. Os fatores que interferem em sua absorção são: má absorção gastrintestinal, secreção biliar, ingestão insuficiente e uso de anticoagulantes, entre outros. As principais fontes de vitamina $\mathrm{K}$ são os vegetais e óleos, sendo esses os responsáveis pelo aumento da absorção da filoquinona. Os alimentos folhosos verde escuro, os preparados à base de óleo, oleaginosas e frutas como o kiwi, abacate, uva, ameixa e figo contêm teores significantes de vitamina $\mathrm{K}$, enquanto que os cereais, grãos, pães e laticínios possuem teores discretos. A ingestão diária de aproximadamente $1 \mu \mathrm{g}$ por quilo de peso é considerada a mais segura, inclusive para a utilização de anticoagulantes orais, em que a concentração estável da vitamina proporciona a eficácia no tratamento. A droga anticoagulante oral geralmente utilizada é a varfarina, administrada como profilática e para tratamento de fenômenos tromboembólicos. Essa intervenção medicamentosa é monitorada pelo tempo de protrombina expresso pela razão normalizada internacional, tendo como objetivo estabelecer a faixa terapêutica entre 2 e 3 , minimizando o risco de hemorragias. $\mathrm{O}$ efeito anticoagulante pode ser reduzido por fatores como ganho de peso, diarréia, vômito, idade menor que 40 anos e consumo excessivo de vitamina $\mathrm{K}$ na dieta alimentar.

Palavras-chave: vitamina $K$, filoquinona, anticoagulação, varfarina.

\section{INTRODUÇÃO}

As vitaminas são substâncias orgânicas presentes em pequena quantidade nos alimentos, tendo por finalidade a participação em variadas reações metabólicas controladas por enzimas e coenzimas. São indispensáveis ao funcionamento do organismo na forma de co-fatores. Em algumas enzimas o co-fator é um participante direto do processo

\begin{abstract}
Vitamin $K$ is a fat-soluble substance, mainly involved in the blood coagulation. It is presented as Phylloquinone (KIpredominant), Dihydrophyloquinone (dK), Menaquinone $\left(K_{2}\right)$, and Menadione $\left(K_{3}\right)$. The factors that interfere with its absorption are: gastrointestinal malabsorption, biliary secretion, inadequate ingestion and anticoagulant use, among others. The main vitamin $K$ sources are vegetables and organic lipids, that are involved in the increased absorption of phylloquinone. Dark green leafy vegetables, usually mixed with oils, nuts and some fruits, including kiwi, avocado, grapes, plums, and figs are rich sources of vitamin $K$, whereas cereals, grains, breads, and dairy products present low amounts. The daily ingestion of approximately $1 \mu \mathrm{\mu g} / \mathrm{kg}$ bodyweight is considered safe, even with concomitant oral anticoagulant use, since stable vitamin concentration contributes to anticoagulant efficacy. The most commonly used oral anticoagulant formation is warfarin, that is indicated to both prophylactic and therapeutic tromboembolic phenomena. It is currently monitored by assessing prothrombin time, after adjusting for the international normalized ratio (INR). Usually, the oral dose is adjusted to set the INR in the range of $2-3$, in order to achieve the treatment objective. The anticoagulating efficacy is influenced by a variety of clinical factors, such as weight gain, diarrhoea, vomiting, age under 40, and excessive vitamin $K$ daily consumption.
\end{abstract}

Keywords: vitamin $K$, phylloquinone, anticoagulation, warfarin.

catalítico, em outras serve como um transportador transitório de algum grupo funcional específico derivado do substrato. Esses co-fatores enzimáticos são essenciais para a ação de muitas enzimas, desempenhando um papel vital no metabolismo celular. O organismo humano promove a síntese de algumas vitaminas, necessitando, no entanto, do suprimento alimentar.

As vitaminas ocorrem na natureza como tal ou sob a

Recebido em 31/07/06. Aprovado, após revisão, em 29/09/06

1. Nutricionista da Divisão de Nutrição e Dietética (DND) do Ambulatório de Síndrome Antifosfolípide (SAF) do Serviço de Reumatologia do Hospital das Clínicas da Faculdade de Medicina da Universidade de São Paulo (USP). Especialista em Saúde Pública e Envelhecimento pela Faculdade de Saúde Pública da USP. 2. Médico assistente, Doutor do Serviço de Reumatologia e Chefe do Ambulatório de SAF do Hospital das Clínicas da Faculdade de Medicina da USP. Endereço para correspondência: Karin Klack, Av. Dr. Enéas de Carvalho Aguiar, 255, $2^{\circ}$ andar, CEP 05403-900, São Paulo, SP, Brasil, telefone/fax: (11) 3069-6332. e-mail: karinnutri@gmail.com 
forma de precursores, que são ingeridos através dos alimentos. As microquantidades necessárias variam em função da idade, sexo, estado fisiológico e atividade física do indivíduo. A necessidade é aumentada nos processos de crescimento, gestação, lactação, condições de esforços intensos e na ocorrência de determinadas doenças. Podem ser classificadas em hidrossolúveis e lipossolúveis, segundo as características físico-químicas e propriedades fisiológicas ${ }^{(1,2,3)}$.

Dentre as vitaminas lipossolúveis encontra-se a vitamina K, que foi descoberta em 1929 por Henrik Dam num estudo com galinhas, no qual pôde observar a hemorragia como sinal característico de uma dieta livre de gorduras. Posteriormente, em 1935, foi relatado por Dam que o sintoma era aliviado pela ingestão de uma substância solúvel em gordura, a qual denominou vitamina $\mathrm{K}$ ou vitamina da coagulação $^{(1,4)}$. A designação vitamina $\mathrm{K}$ deriva da primeira letra da palavra dinamarquesa koagulation ${ }^{(5)}$. Em 1939, Dam e Doisy isolaram-na da alfafa, determinando sua estrutura: 2 metil-3phytyl-1,4naftoquinona ${ }^{(4,6)}$. A vitamina Kencontrase em alimentos animais e vegetais, com a maior concentração em folhas verde escura ${ }^{(7)}$. As formas da vitamina $\mathrm{K}$ são: - Filoquinona (vitamina $\mathrm{K}_{1}$ ) que é a forma predominante ${ }^{(8-11)}$, presente nos vegetais, sendo os óleos vegetais e as hortaliças suas fontes mais significativas ${ }^{(6-8,11-13)}$.

- Dihidrofiloquinona (dK), formada durante a hidrogenação comercial de óleos vegetais $^{(7,11)}$.

- Menaquinona (vitamina $\mathrm{K}_{2}$ ), sintetizada por bactérias, podendo variar de $\mathrm{MK}_{4}$ a $\mathrm{MK}_{13}$ (série de vitaminas designadas $\mathrm{MK}_{-\mathrm{n}}$, sendo n o número de resíduos isoprenóides). Presente em produtos animais e alimentos fermentados ${ }^{(10,11,14-17)}$.

- Menadiona (vitamina $\mathrm{K}_{3}$ ) que é um composto sintético a ser convertido em $\mathrm{K}_{2}$ no intestino ${ }^{(4,6,18,19)}$.

Esse trabalho teve como objetivo revisar a literatura sobre a vitamina $\mathrm{K}$, metabolismo, biodisponibilidade, recomendações, teores presentes nos alimentos e a interferência em tratamento com o anticoagulante oral varfarina sódica.

\section{METABOLISMO}

A vitamina Ké absorvida no intestino delgado e transportada pelas vias linfáticas. Necessita de um fluxo normal de bile e suco pancreático, além de um teor adequado de gordura na dieta ${ }^{(5)}$. Alguns fatores podem interferir na absorção como a fisiologia do indivíduo, doenças específicas, má absorção gastrintestinal, secreção biliar, estado nutricional, ingestão insuficiente das fontes dessa vitamina, uso de anticoagulantes cumarínicos, nutrição parenteral total (NPT) e ingestão de megadoses de vitaminas A e E (antagonistas da vitamina $\mathrm{K})^{(19)}$. As maiores lipoproteínas carreadoras da vitamina $\mathrm{K}$ são os triglicérides, explicando a relação entre filoquinona e triglicérides plasmáticos ${ }^{(6,15)}$. Independentemente da dose consumida, 20\% é excretada pela urina em três dias, enquanto que entre 40 e $50 \%$ pelas fezes. Esse catabolismo mostra a rápida depleção das reservas hepáticas em pessoas com dieta pobre em vitamina $\mathrm{K}^{(20)}$.

A menor concentração plasmática encontra-se na terceira década de vida para ambos os sexos, sendo aumentada após esse período ${ }^{(6)}$. Os indivíduos acima de 60 anos (principalmente as mulheres) apresentam concentrações maiores que os abaixo de 40 anos. Isso pode se dever ao fato de que as pessoas da terceira idade consomem mais filoquinona que os de 20 a $50 \operatorname{anos}^{(8,12)}$. Foi relatado que os ossos podem agir como repositores de filoquinona e menaquinona em pessoas idosas ${ }^{(15)}$. A deficiência da vitamina $\mathrm{K}$ é detectada através de sintomas como hemorragias, equimoses, melena, hematúria, hematêmese e osteoporose ${ }^{(6)}$.

\section{FUNÇÕES DA VITAMINA K}

A vitamina $\mathrm{K}$ atua como co-fator para a carboxilação de resíduos específicos de ácido glutâmico para formar o ácido gama carboxiglutâmico (Gla), aminoácido presente nos fatores de coagulação (fatores II, VII, IX e X) $)^{(6,7,15)} \mathrm{e}$ que se apresenta ligado ao cálcio, podendo, ainda, regular a disposição do elemento cálcio na matriz óssea como parte da osteocalcina. A osteocalcina (proteína do osso) é uma das mais freqüentes proteínas não-colagenosas na matriz extracelular do osso. Sua dosagem no sangue constitui importante marcador biológico da atividade osteoblástica. Há evidências de que a vitamina K seja importante no desenvolvimento precoce do esqueleto e na manutenção do osso maduro sadio ${ }^{(6,15)}$.

Quanto à coagulação sanguínea, ocorre a transformação do fibrinogênio em fibrina insolúvel com a interferência de uma enzima proteolítica (trombina), que se origina da protrombina (fator II), através de fatores dependentes da vitamina $\mathrm{K}$ : a pró-convertina (fator VII), o fator anti-hemofílico B (fator IX) e o fator Stuart (fator X). A vitamina Kinflui, ainda, na síntese de proteínas presentes no plasma, rins e talvez outros tecidos ${ }^{(5)}$. A carboxilação da vitamina K está envolvida, portanto, na homeostase, metabolismo ósseo e crescimento celular ${ }^{(7,16,21)}$. Estudos prévios mostraram efeitos inibitórios do crescimento de várias células neoplásicas (mieloma - human myeloma cell lines e non-myelomatous cell lines), provocados pela vitamina $\mathrm{K}_{2}^{(22)}$ e redução do risco de eventos mutagênicos na fase de proliferação celular rápida em fetos e recém-nascidos 
pré-termos. Alguns estudos apontam a hipovitaminose K como responsável pela hemorragia retroplacentária de abortamentos habituais ${ }^{(5)}$.

\section{NÍVEIS SÉRICOS DA VITAMINA K}

Nas pessoas saudáveis em jejum, a concentração de vitamina K plasmática (filoquinona) é menor que $1 \mathrm{ng} / \mathrm{ml}$ (1 $\mathrm{ng} / \mathrm{ml}=2,2 \mathrm{nmol} / \mathrm{l})$, não existindo proteína carregadora específica. Medidas como a dosagem da vitamina K plasmática podem ser utilizadas, porém, os métodos disponíveis não são práticos para uma avaliação rotineira ${ }^{(5)}$. A concentração da filoquinona plasmática não se correlaciona adequadamente com o estado nutricional da vitamina $\mathrm{K}$, pois é dependente da ingestão recente da vitamina em 24 horas $^{(8)}$.

A excreção urinária de Gla, proteína induzida pela deficiência ou antagonismo de vitamina $\mathrm{K}$, e a osteocalcina pouco carboxilada - under carboxylated osteocalcin (ucOc) - são os indicadores do estado nutricional. A ucOc é o marcador, mais sensível, no antagonismo à vitamina K resultante da inibição da enzima epóxi-redutase (pelo tratamento com a varfarina), que produz efeito diverso na produção de proteínas por diferentes tecidos, juntamente com o déficit na ingestão de vitamina $\mathrm{K}$, em que a osteocalcina circulante parece ser a primeira proteína Gla a aparecer no plasma, na forma descarboxilada ${ }^{(6)}$.

\section{BIODISPONIBILIDADE DA VITAMINA K}

A biodisponibilidade é definida como a proporção da vitamina ingerida que sofre a absorção intestinal e conseqüente aproveitamento pelo corpo. A absorção da filoquinona presente nos vegetais é um processo lento, sendo influenciado por fatores digestivos. Já a presença de gorduras na dieta possibilita um aumento na absorção (podendo conter de 30-60 $\mu \mathrm{g}$ de dK em $100 \mathrm{~g}$ do alimento), possivelmente pelo estímulo da secreção biliar e formação de micelas ${ }^{(6,8,12,19)}$. O fato de a filoquinona estar associada a tecidos que realizam a fotossíntese faz com que os vegetais contenham os maiores teores dessa substância. Trinta por cento do total do teor da vitamina K nos alimentos se apresentam sob a forma de $\mathrm{dK}$, mas é menos ativa biologicamente que a filoquinona ${ }^{(12)}$. A casca das frutas e dos vegetais parece conter maiores concentrações da vitamina que a polpa ${ }^{(6,9)}$. As preparações vegetais secas e congeladas não diferem do conteúdo da vitamina em comparação aos vegetais frescos ${ }^{(6)}$. A vitamina $K$ presente nos óleos vegetais é estável ao calor, mas é destruída pela luz, tanto natural quanto fluorescente. A exemplo disso, foi verificado que o óleo de canola perde $87 \%$ da vitamina K após ser exposto por dois dias à luz solar ${ }^{(6,23)}$

A quantidade de vitamina $K_{1}$ presente nos alimentos é influenciada por fatores como a fertilização e condições do solo, clima, área geográfica, estado de maturação e variação sazonal, sendo verificado que os meses de verão aumentam mais a quantidade da filoquinona que os meses de inverno ${ }^{(6,}$ ${ }^{9}$. Alguns estudos, entretanto, contestam essa versão ${ }^{(8)}$.

\section{FONTES ALIMENTARES}

Um dos métodos utilizados para a determinação da vitamina $\mathrm{K}$ nos alimentos é a cromatografia líquida de alta eficiência. Pode ser executado à temperatura ambiente e sem derivação das substâncias, utilizando a detecção por propriedades de fluorescência dos compostos que realizam a função das vitaminas ${ }^{(2,11)}$.

A vitamina $\mathrm{K}$, nos alimentos, pode variar de $1 \mu \mathrm{g}$ por 100 $\mathrm{ml}$ de leite a $400 \mu \mathrm{g}$ por $100 \mathrm{~g}$ em hortaliças (Tabela $\mathrm{l}$ ). As sopas e carnes são fontes pobres de filoquinona ${ }^{(6,7,10,15)}$ mas, dependendo dos ingredientes da preparação, as sopas, os queijos, carnes processadas e pratos mistos podem ter seus teores elevados $^{(10)}$. Os leites não são considerados fonte, assim como os queijos que contêm de 5-20 $\mu \mathrm{g} / 100 \mathrm{~g}$ de menaquinona $\mathrm{MK}_{8 \mathrm{e} 9}{ }^{(15,16,24)}$. Os peixes, cereais e grãos contêm pequenas quantidades, porém têm seu teor elevado em preparações com adição de óleos ${ }^{(14,15)}$. A farinha de aveia crua tem concentração mais alta de $\mathrm{K}_{1}$ que a cozida, devido ao efeito de diluição criado na adição de água durante a preparação. Os pães e o arroz são fontes pobres ${ }^{(14)}$. Os tubérculos e bulbos como a batata, rabanete e cebola contêm traço de filoquinona, sendo que entre as raízes, somente a cenoura contém teor maior ou igual a $8,3 \mu \mathrm{g} / \mathrm{l} 00 \mathrm{~g}$. As frutas cítricas contêm baixos teores, tendo como exceção o kiwi, abacate, ameixa seca, figo, amora silvestre, blueberries e as uvas, que contêm de 15,6 a $59,5 \mu \mathrm{gK} / 100$ g. Os sucos de frutas são as menores fontes de vitamina $\mathrm{K}^{(18,24)}$.

Os lanches e sobremesas contêm valores intermediários de filoquinona, variando de 2,9-20 $\mu \mathrm{g}$ e 0-14 $\mu \mathrm{g} / \mathrm{l} 00 \mathrm{~g}$ de alimento, respectivamente. Alimentos cozidos e processados contêm de moderada a alta quantidade, levando-se em consideração que, geralmente, o consumo diário desses alimentos pode ultrapassar $100 \mathrm{~g}$, tornando-os fontes significativas $^{(24)}$. Os produtos derivados do tomate que contêm salsa, óleo ou ingredientes como ervas em sua composição, possuem teores maiores da vitamina que os demais. Certas oleaginosas como nozes e caju têm teores significantes de vitamina $\mathrm{K}^{(8,9)}$. As folhas de chá e os grãos do café também possuem quantidades significativas de filoquinona ${ }^{(25)}$. Foi constatado que há diferentes concentrações de vitamina $\mathrm{K}_{1}$ 
TABELA 1

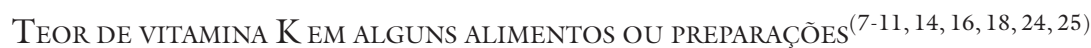



* ND = Não Detectável 
entre duas marcas de chá preto e de chá de ervas verdes, indicando que fatores como estocagem, processamento, $\mathrm{CO}^{-}$ lheita e origem geográfica podem interferir no conteúdo de vitamina $\mathrm{K}_{1}$ nos chás. Em relação ao café, o conteúdo pode variar de 0,5-25 $\mu \mathrm{g} / 100 \mathrm{~g}$. A vitamina $\mathrm{K}_{1}$ presente nos grãos de café depois do preparo foi significativamente menor que a concentração anterior ao preparo. Mesmo que as folhas de chá e os grãos de café contenham alta concentração de vitamina $\mathrm{K}$, a bebida pronta para consumo não é considerada como fonte dessa vitamina ${ }^{(8)}$. O café instantâneo não é fonte nem antes, nem após o preparo ${ }^{(25)}$.

Quanto aos alimentos ricos em vitamina $\mathrm{K}$, o grupo dos vegetais folhosos verde escuro contém a maior concentração, como, por exemplo, espinafre, brócolis e alguns tipos de alface, variando de $0,03-440 \mu \mathrm{gK}_{1} / 100 \mathrm{~g}$ de alimento $^{(8,9)}$. A preparação de creme de espinafre foi considerada uma das maiores fontes, contendo $292 \mu \mathrm{gK} / / 100 \mathrm{~g}$ de alimento $^{(24)}$. As segundas maiores fontes de filoquinona são os óleos e gorduras (0,3-193 $\mu \mathrm{gK}_{1} / 100 \mathrm{~g}$ de alimento). Por isso, ao serem acrescentados aos alimentos ou preparações, ocorre aumento da vitamina $\mathrm{K}^{(8,10)}$. A manteiga pode conter até $10 \mu \mathrm{g} \mathrm{em}$ $100 \mathrm{~g}$, enquanto que os óleos vegetais de canola e soja de 127-193 $\mu$ g por 100 g. Os óleos de soja, canola, algodão e oliva têm maiores teores de vitamina $\mathrm{K}_{1}$ que os de amendoim e de milho ${ }^{(8,9,11,24)}$. As gorduras derivadas de óleos vegetais como a margarina, maionese e temperos para salada contêm mais filoquinona comparada à gordura de origem animal, como a manteiga, por exemplo. Os produtos fermentados à base de soja contêm quantidades importantes ${ }^{(15,16,24)}$. Os fast foods como hambúrgueres, pizzas, sanduíches de frango ou de peixe e petiscos contêm altos teores de filoquinona $(5,9$ a $19,3 \mu \mathrm{g} / 100 \mathrm{~g}$ ) comparados às demais carnes ${ }^{(7,11)}$, assim como os produtos processados que contêm óleo ou gordura como panquecas, wafles e lanches matinais que também contêm alta concentração ${ }^{(14)}$.

A dK é encontrada em altas doses nos nuggets de frango e tender (15,9 e $20 \mu \mathrm{gdK} / 100 \mathrm{~g}$, respectivamente), sendo também identificada em fórmulas infantis preparadas com gorduras $(30-60 \mu \mathrm{gdK} / 100 \mathrm{~g} \text { de alimento })^{(7,8,11)}$.

\section{DICAS DIETÉTICAS}

- Utilizar a mínima quantidade possível de óleos e gorduras, como adição no preparo dos alimentos;

- Evitar o consumo de produtos industrializados à base de óleos, salsa ou ervas (molhos prontos, sopas de pacote, temperos concentrados em tabletes);

- Consumir alimentos conservados em salmoura ao invés da conservação em óleo (ex: atum em lata);

- Remover cascas de frutas e legumes, por possuírem maior concentração da vitamina K que a polpa;

- Utilizar, preferivelmente, queijos ou geléias nas pequenas refeições, ao invés de manteigas e margarinas;

- Evitar a substituição de refeições como almoço e jantar, por lanches e petiscos;

- Manter constante a ingestão diária de vitamina K, evitando grandes variações quantitativas, pois os alimentos fonte de filoquinona também são importantes para o controle de distúrbios metabólicos como as dislipidemias, por exemplo ${ }^{(26)}$.

\section{RECOMENDAÇÕES DIETÉTICAS}

A ingestão diária recomendada (IDR) é a quantidade de vitaminas e de outros nutrientes que deve ser consumida diariamente para atender às necessidades nutricionais da maior parte dos indivíduos e grupos de pessoas da população sadia (Tabelas 2 e 3$)^{(27,28)}$.

TABELA 2

ANVISA (AgÊncia Nacional de Vigilância Sanitária) RESOLUÇÃO RDC No 269 dE 22/09/2005

\begin{tabular}{lll}
\hline & Idade & $\boldsymbol{\mu g}$ vit. $\mathbf{~ g} / \mathbf{d i a}$ \\
\hline Lactentes & $0-6$ meses & 05 \\
& $7-11$ meses & 10 \\
Crianças & $1-3$ anos & 15 \\
& $4-6$ anos & 20 \\
\hline Adultos & $7-10$ anos & 25 \\
Gestantes & & 65 \\
\hline Lactantes & & 55 \\
\hline
\end{tabular}

Fonte: www.anvisa.gov.br

TABELA 3

NATIONAL ACADEMY PRESS

\begin{tabular}{|c|c|c|}
\hline Idade & Mulheres ( $\mu \mathrm{g}$ vit. $\mathrm{Kg} / \mathrm{dia}$ ) & Homens ( $\mu$ g vit. $\mathrm{Kg} / \mathrm{dia}$ ) \\
\hline $0-6$ meses & 2,0 & \\
\hline $7-12$ meses & 2,5 & \\
\hline $1-3$ anos & 30 & \\
\hline $4-8$ anos & 55 & \\
\hline $9-13$ anos & 60 & 60 \\
\hline $14-18$ anos & 75 & 75 \\
\hline $19-30$ anos & 90 & 120 \\
\hline $31-50$ anos & 90 & 120 \\
\hline $50-70$ anos & 90 & 120 \\
\hline$>70$ anos & 90 & 120 \\
\hline $\begin{array}{l}\text { Gestação: } \leq 18 \\
\text { anos }\end{array}$ & 75 & --- \\
\hline $19-30$ anos & 90 & --- \\
\hline $31-50$ anos & 90 & --- \\
\hline Lactação: $\leq 18$ anos & 75 & --- \\
\hline $19-30$ anos & 90 & --- \\
\hline
\end{tabular}

Fonte: Dietary reference intakes for vitamin $K$. Food and nutrition board. Institute of medicine - Nat Acad Press, 162-96, 2001. 
No tratamento com anticoagulantes orais, o paciente deve ter uma ingestão equilibrada e constante da vitamina $\mathrm{K}$. Através da idade do paciente, verifica-se nas tabelas de recomendação o total de microgramas de vitamina $\mathrm{K}$ indicado ou utiliza-se $1 \mu \mathrm{g} / \mathrm{Kg}$ de peso corpóreo ao dia, que é uma quantidade considerada segura e adequada, pela maioria dos estudos ${ }^{(8,15)}$.

Como exemplo, um paciente anticoagulado de $80 \mathrm{Kg}$ deve receber, aproximadamente, $80 \mu \mathrm{g}$ de vitamina $\mathrm{K}$ ao dia. Pode-se alcançar essa quantidade oferecendo uma dieta baseada na tabela com os teores de vitamina K (Tabela 1 ), contendo:

- Desjejum: café, leite, pão e um alimento fonte de vitamina $\mathrm{K}$ (margarina em média quantidade);

- Almoço: fontes como um pires (chá) de folhas cruas (não utilizando óleo ou gorduras como tempero), arroz, feijão, uma porção de carne não frita e uma sobremesa (Evitar as frutas que são fontes da vitamina);

- Lanches intermediários: sem nenhum alimento fonte de vitamina $\mathrm{K}$;

- Jantar: o mesmo que o almoço, podendo alterar a salada para um legume cru e consumir um alimento fonte em pequena quantidade ( $1 / 2$ pires de brócolis cozido);

- Utilizar alimentos com baixo teor de gordura e restringir o máximo possível os óleos e gorduras no preparo das refeições.

Com a possibilidade de uma orientação com nutricionista, o paciente adquire informações quanto a uma maior variabilidade alimentar de fontes de filoquinona, orientação de doses seguras, segundo a faixa etária e níveis da Razão Normalizada Internacional (INR), além de acompanhamento individualizado para tratamento e prevenção de co-morbidades.

Não é recomendado oferecer menos que $1 \mu \mathrm{g}$ vitamina $\mathrm{K} / \mathrm{Kg}$ ao dia, pois estudos mostraram que a redução acentuada da ingestão não exerce claro benefício no controle da INR, além de aumentar os riscos para a osteoporose ${ }^{(25)}$.

Estudos concluíram que, particularmente na velhice, a recomendação de vitamina K para manter a função óssea pode ser maior que a necessária para a coagulação.

\section{INTERAÇÃO DA VITAMINA K COM ANTICOAGULAÇÃO ORAL}

As drogas antivitamina K (AVK), cumarínicas ou anticoagulantes orais, como por exemplo a mais comumente usada varfarina (composto 4-hidroxicumarina), são administradas, às vezes, por mais de $60 \operatorname{anos}^{(26)}$, como profiláticas e para tratamento de fenômenos tromboembólicos ${ }^{(15,20,29,}$ 30), inibindo a enzima hepática vitamina K epóxi-redutase, os fatores II, VII, IX e X e proteínas C e S ${ }^{(6,17,20,31)}$.

\section{CICLO DA VITAMINA K}

Para que os fatores II, VII, IX, X, proteínas C e S se tornem ativos é necessário que ocorra a gama carboxilação do ácido glutâmico, possibilitando assim a adesão dessas proteínas aos fosfolípides de superfície, acelerando o processo de coagulação ${ }^{(21,32)}$. A vitamina $\mathrm{Kem}$ forma reduzida $\left(\mathrm{KH}_{2}\right)$ atua como co-fator essencial para o processo da gama carboxilação dos fatores de coagulação. Neste processo, a $\mathrm{KH}_{2}$ é oxidada a epóxi-vitamina $\mathrm{K}$ e a seguir retorna a $\mathrm{KH}_{2}$ pela ação de duas redutases, completando o ciclo da vitamina $\mathrm{K}$. A varfarina inibe a ação das duas redutases, reduzindo a quantidade de vitamina $\mathrm{KH}_{2}$ disponível, limitando o processo de carboxilação (Figura 1$)^{(26)}$.

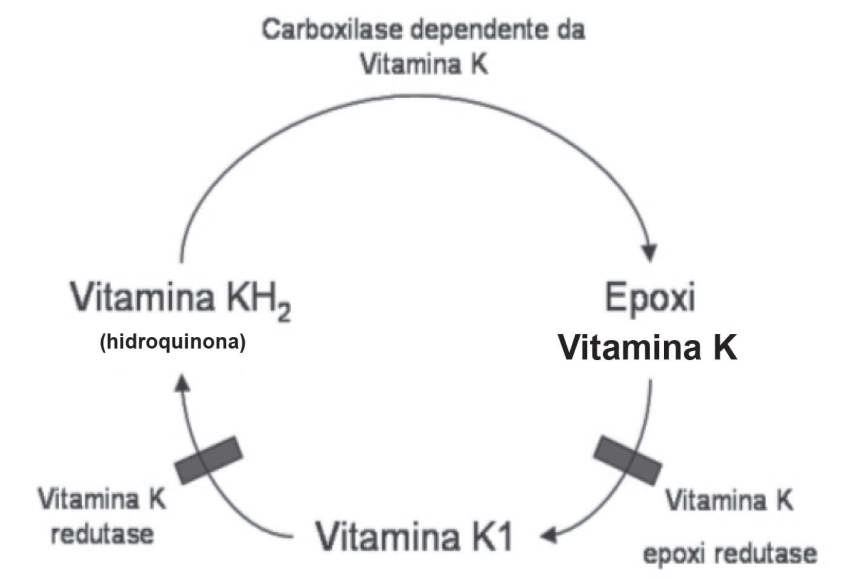

Figura 1 - Ciclo da vitamina K. A varfarina inibe a ação das redutases (barras), inibindo a síntese de vitamina $\mathrm{K} 1$ e vitamina $\mathrm{KH}_{2}$.

\section{RECOMENDAÇÕES}

As AVK são recomendadas no tratamento de tromboses arteriais e venosas, embolia pulmonar, doenças cardiovasculares, uso de válvulas cardíacas metálicas e síndrome antifosfolípide, a qual representa o grupo de pacientes que requerem mais intensivamente a terapia de anticoagulação $\operatorname{oral}^{(20,21,33)}$. A monitoração é realizada pela medida do tempo de protrombina (TP) expresso pela IRN, demonstrando a eficácia do tratamento anticoagulante. O controle da ação da varfarina, baseado na IRN é de difícil controle devido às freqüentes variações nos níveis de anticoagulação, causadas por fatores intrínsecos como a carga genética relacionada ao metabolismo da droga, idade e capacidade de absorção da vitamina $\mathrm{K}$ e de fatores extrínsecos como a dieta alimentar, interação medicamentosa, estilo de vida e presença de co-morbidades ${ }^{(21,26)}$. 
Os fatores responsáveis pela redução da resposta do IRN ao cumarínico são edema, resistência hereditária à cumarina, hiperlipemia, hipotireoidismo e síndrome nefrótica ${ }^{(34)}$. A dosagem do anticoagulante deve ser individualizada de acordo com a sensibilidade do indivíduo à droga conforme indicado pelo IRN ${ }^{(35)}$. O objetivo desta intervenção medicamentosa é estabelecer a faixa terapêutica do IRN que compreende entre 2 e 3 , na grande maioria dos estudos clínicos, minimizando o risco de hemorragias, sem elevar os riscos trombóticos ${ }^{(21,30,32-34)}$.

Portadores de disfunção hepática são mais susceptíveis aos cumarínicos por terem produção deficiente de fatores de coagulação, assim como estados hipermetabólicos que ampliam a ação da varfarina, doenças consuptivas, insuficiência renal e aumento da ingestão de álcool ${ }^{(5,21,26,36)}$. Em idosos há um aumento da disponibilidade da droga pela redução da concentração de albumina sérica e redução do metabolismo hepático ${ }^{(26,32)}$, facilitando sua ação. A idade acima de 75 anos apresenta riscos aumentados de hemorragia intracraniana ${ }^{(36)}$. Na gestação, a exposição à varfarina deve ser evitada no primeiro trimestre (entre a $6^{\underline{a}}$ e $12^{\text {a }}$ semanas) por atravessar a placenta e poder causar a embriopatia varfarínica (caracterizada pela hipoplasia nasal e/ou a não consolidação das epífises) ${ }^{(37)}$, além de anomalias do sistema nervoso central (SNC). No período pós-parto, pode-se retornar ao uso, pois, segundo alguns estudos, a varfarina não é encontrada no leite materno.

\section{METABOLISMO E ABSORÇÃO}

A varfarina é metabolizada no fígado por meio da hidroxilação e conjugação realizadas por enzimas microssomais. É absorvida por completo, chegando à circulação sanguínea nas primeiras quatro horas, iniciando o efeito anticoagulante em 24 horas $^{(20)}$.

\section{INTERAÇÕES MEDICAMENTOSAS}

As drogas que interagem com a ação da varfarina podem tanto potencializar, como inibir a atividade coagulante (Tabela 4). A interação farmacológica ocorre com a inibição da atividade da droga e desta no trato digestivo, aumento da produção de enzimas hepáticas ou redução da capacidade de ligação da varfarina às proteínas plasmáticas, aumentando a quantidade da droga livre no plasma ${ }^{(26)}$.

- Fitoterápicos com efeito anticoagulante em potencial: alfafa, angélica, semente de anis, arnica, aipo, boldo, camomila, castanha-da-Índia, dente-de-leão, gengibre, gingko biloba, salsa, tamarindo, salgueiro, rábano, urtiga, álamo e sálvia.
TABELA 4

INTERAÇÕES MEDICAMENTOSAS COM ANTICOAGULANTES ORAIS

\begin{tabular}{|c|c|c|c|}
\hline \multicolumn{4}{|c|}{ REDUÇÃO DO EFEITO ANTICOAGULANTE } \\
\hline Azatioprina & Corticosteróides & $\begin{array}{l}\text { Hidróxido de } \\
\text { alumínio }\end{array}$ & Rifampicina * \\
\hline Barbitúricos & Dicloxacilina * & Fenitoína * & Sucrafalto \\
\hline Carbamazepina * & Diuréticos & Fenobarbital ${ }^{*}$ & Vitamina C \\
\hline Ciclofosfamida & $\begin{array}{l}\text { Drogas } \\
\text { antitireóideas }\end{array}$ & Mercaptopurina & Vitamina K \\
\hline Colestiramina & Etanol (uso crônico) & Quinidina & \\
\hline \multicolumn{4}{|c|}{ AUMENTO DO EFEITO ANTICOAGULANTE } \\
\hline AAS & Antifúngicos & $\begin{array}{l}\text { Hormônios } \\
\text { tireoidianos }\end{array}$ & Salicilatos \\
\hline AINH em geral & Cimetidina * & Isoniazida & SMX/TMP* \\
\hline Alopurinol & Clofibrato & Metronidazol ${ }^{*}$ & Ticlopidina \\
\hline Amiodarona * & Clorpropamida & Omeprazol * & Tamoxifeno \\
\hline Andrógenos & Etanol (agudo) & Paracetamol & Vitamina $\mathrm{E}$ \\
\hline $\begin{array}{l}\text { Antidepressivos } \\
\text { tricíclicos }\end{array}$ & Eritromicina & $\begin{array}{l}\text { Metilprednisolona } \\
\text { (pulso) }\end{array}$ & Zafirlucaste * \\
\hline $\begin{array}{l}\text { Antidepressivos } \\
\text { (ISRS) }{ }^{*}\end{array}$ & Fluconazol * & Quinolonas * & Zileuton * \\
\hline
\end{tabular}

AINH: antiinflamatório não-hormonal.

ISRS: inibidores seletivos de recaptação de serotonina.

*Via interação com citocromo P450 2c9(38,39)

- Fitoterápicos com propriedades coagulantes ou fibrinolíticas: agrimônia, visco, milefólio e ginseng ${ }^{(35)}$.

- Fatores que reduzem o efeito anticoagulante: ganho de peso, diarréia, vômito e idade inferior a $40 \operatorname{anos}^{(32)}$. Altas doses de vitamina $\mathrm{K}$ na dieta, pois resultam em estado de coagulação fora do limite terapêutico. Portanto, deve-se ter um controle dos alimentos fontes de vitamina $\mathrm{K}$, mantendo um limiar adequado(10, 13, 14, 18, 20, 29, 33).

A presença das AVK, juntamente com o baixo consumo de vitamina $\mathrm{K}$ na dieta, parece afetar mais intensamente a osteocalcina descarboxilada ${ }^{(6)}$.

\section{CONSIDERAÇÕES FINAIS}

Os teores da vitamina $\mathrm{K}$ em verduras e hortaliças não contêm diferenças significativas em comparação aos teores presentes nos óleos. Portanto, ao orientar indivíduos anticoagulados, deve ser levado em consideração que as gorduras não possuem o valor nutritivo dos vegetais, sendo o alvo principal a ser reduzido na dieta alimentar.

Espera-se que, futuramente, a gordura hidrogenada seja 
minimizada ou mesmo eliminada dos produtos alimentares, reduzindo o teor de dihidrofiloquinona para, assim, oferecer mais opções aos pacientes em uso de anticoagulantes.

A literatura nacional é bastante escassa no que se refere à vitamina K. Em razão disso, faz-se necessária a realização de novos estudos e aprimoramento da tabela de composição, para ampliar o conhecimento sobre os teores de vitamina $\mathrm{K}$ nos alimentos brasileiros.

Declaramos a inexistência de conflitos de interesse.

\section{REFERÊNCIAS}

1. Franco G: Tabela de composição química dos alimentos. Ed Liv Atheneu, RJ 9a ed, 1999.

2. Paixão JA, Stamford TLM: Vitaminas lipossolúveis em alimentos - uma abordagem analítica. Quim Nova 27: 96-105, 2004.

3. Lehninger AL, Nelson DL, Cox MM: Princípios de bioquímica. São Paulo, Sarvier 3, 2002.

4. Bentley R, Meganathan R: Biosynthesis of vitamin K (menaquinone) in bacteria. Am Soc Micr 46: 241-80, 1982.

5. Dutra-de-Oliveira JE, Marchini JS: Ciências nutricionais. São Paulo, Sarvier, 1998.

6. Dores SMC, Paiva SAR, Campana AO: Vitamina K: metabolismo e nutrição. Rev Nutr 14: 207-18, 2001.

7. Elder SJ, Haytowitz DB, Howe J, Peterson JW, Booth SL: Vitamin $\mathrm{K}$ contents of meat, dairy, and fast food in the U.S. diet. J Agric Food Chem 54: 463-7, 2006.

8. Booth SL, Suttie JW: Dietary intake and adequacy of vitamin $\mathrm{K}_{1}$. J Nutr, Bethesda 128: 785-8, 1998.

9. Damon M, Zhang NZ, Haytowitz DB, Booth SL: Plylloquinone (vitamin $\mathrm{K}_{1}$ ) content of vegetables. J Food Comp and An 18: 751-8, 2005.

10. Dumont JF, Peterson JW, Haytowitz DB, Booth SL: Phylloquinone and dihydrophylloquinone contents of mixed dishes, processed meats, soups and cheeses. J Food Comp and An 16: 595-603, 2003.

11. Weizmann N, Peterson JW, Haytowitz DB, Pehrsson PR, Jesus VP, Booth SL: Vitamin K content of fast foods and snack foods in the U.S. diet. J Food Comp and An 17: 379-84, 2004.

12. Booth SL: Vitamin K: another reason to eat your greens. USDA Agr Res Serv 48: 16-7, 2000.

13. Greenblatt DJ, Moltke LL: Interation of warfarin with drugs, natural substances, and foods. J Clin Pharm 45: 127-32, 2005.

14. Ferreira DW, Haytowitz DB, Tassinari MA, Peterson JW, Booth SL: Vitamin K contents of grains, cereals, fast-food breakfasts, and baked goods. J Food Sc 71: 66-70, 2006.

15. Shearer MJ: Vitamin K. The Lancet 345: 229-34, 1995.

16. Smith CB, Price RJG, Fenton ST, Harrington DJ, Shearer MJ: Compilation of a provisional UK database for the phylloquinone (vitamin $\mathrm{K}_{1}$ ) content of foods. Brit J Nutr 83: 389-99, 2000.

17. Wallin R, Martin LF: Vitamin K-dependent carboxylation and vitamin K metabolism in liver - effects of warfarin. The Am Soc Clin Invest 76: 1879-84, 1985.

18. Dismore ML, Haytowitz DB, Gebhardt SE, Peterson JW, Booth SL: Vitamin K content of nuts and fruits in the U.S. diet. J Am Diet Assoc 103: 1650-2, 2003.

19. Mourão DM, Sales NS, Coelho SB, Santana HMP:
Biodisponibilidade de vitaminas lipossolúveis. Rev Nutr 18: 529-39, 2005.

20. Melchior C: Nutrição e anticoagulantes orais - implicações clínicas. IMEN - Inst Met e Nutr, 2006.

21. Triplett DA: Current recommendation for warfarin therapy - use and monitoring. Med Clin of North Am 82: 601-11, 1998.

22. Tsujioka T, Miura Y, Otsuki T, et al: The mechanisms of vitamin $\mathrm{K}_{2}$-induced apoptosis of myeloma cells. The Hem J 91: 613-9, 2006.

23. Ferland G, Sadowsky JA: The vitamin $\mathrm{K}_{1}$ (phylloquinone) content of edible oils: effects of heating and light exposure. J Agr Food Chem 40: 1869-73, 1992.

24. Booth SL, Sadowski JA, Pennington JAT: Phylloquinone (vitamin $\mathrm{K}_{1}$ ) content of foods in the U.S. food and drug administration's total diet study. J Agr Food Chem 43: 1574-9, 1995.

25. Booth SL, Madabushi HT, Davidson KW, Sadowski JA: Tea and coffee brews are not dietary sources of vitamin $\mathrm{K}_{1}$ (phylloquinone). J Am Diet Assoc 95: 82-3, 1995.

26. Tondato $\mathrm{F}$ : Interação de fármacos e alimentos com warfarina. Rev Soc Cardiol 5: 770-8, 2004.

27. Resolução RDC no 269. ANVISA - Ag Nac Vig San, 2005. anvisa@gov.br.

28. Dietary Reference intakes for vitamin A, vitamin $\mathrm{K}$, arsenic, boron, chromium, copper, iodine, iron, manganese, molybdenum, nickel, silicon, vanadium, and zinc. Food and nutrition board. Institute of Medicine. Nat Acad Press: 162-96, 2000.

29. Flamingo RA: Interações droga-nutriente. Nutrocl $2^{\underline{a}}$ ed, 2005.

30. Lourenço DM, Morelli VM, Vignal CV: Tratamento da superdosagem de anticoagulantes orais. Arq Bras Card 70: 9-13, 1998.

31. Wallin R, Martin LF: Warfarin poisoning and vitamin $\mathrm{K}$ antagonism in rat and human liver. Biochem J 241: 389-96, 1987.

32. Blann AD, Landray MJ, Lip GYH: Abc of antithrombotic therapy; an overview of antithrombotic therapy. J list BMJ 325 : 762-5, 2002.

33. Wilson SE, Watson HG, Crowther MA: Low-dose oral vitamin $\mathrm{K}$ therapy for the management of asymptomatic patients with elevated international normalized ratios: a brief reviews. Can Med Assoc J 170: 821-4, 2004.

34. Erkan D, Ortel TL, Lockshin MD: Warfarin in antiphospholipid syndrome - time to explore new horizons. J Rheumatol 32: 208-12, 2005.

35. Bulário eletrônico da Anvisa. Ministério da Saúde. http: www. bulario.bvs.br, 2004.

36. Levine MN, Raskob G, Beyth RJ, Kearon C, Schuhman S: 
Hemorrhagic complications of anticoagulant treatment - the seventh ACCP conference on antithrombotic and thrombolytic therapy. Chest 126: 2875-310, 2004.

37. Silveira PRM: Trombose venosa profunda e gestação: aspectos etiopatogênicos e terapêuticos. J Vas Br 1: 65-70, 2002.
38. Green GB, Harris IS, Lin GA, Moylan KC: The Washington manual of medical therapeutics. Dep Med - Univ Sch Med, 2004.

39. Lacy CF, Armstrong LL, Goldman MP, Lance LL: Drug information hand book. Lexi-comp, Inc. 2004. 